\title{
A Case Study on Mathematical Literacy of Prospective Elementary School Teachers
}

\section{Gusti Putu Suharta}

Prof., Ganesha University of Education, Indonesia, igpsuharta@yahoo.com

\section{Made Suarjana}

Ganesha University of Education, Indonesia, suarjana_undiksha@yahoo.co.id

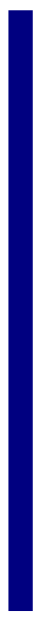
The purpose of this study is to describe Mathematical Literacy (ML) of Prospective Elementary School Teachers with attention to aspects of mathematical skills and gender. The type of research is qualitative with the research design of Case Study. Respondents are assigned 12 Prospective Elementary School Teachers, consisting of 6 men and 6 women. The instruments used to collect data on ML are tests, and interview guidelines. The collected data were analyzed descriptively. The results of this study are: (1) ML of Prospective Elementary School Teachers which can be seen from the aspect of mathematical skills and gender is categorized as low, respondents having strong mathematical skills indicate a better ML than respondents having weak mathematical skills, and female respondents indicate better ML than male respondents; (2) in terms of Content, the highest score is achieved on the Numbers Content, the weakest Content is in terms of Algebra and Function, while the strongest content is in the field of Probability and Statistics; (3) in terms of Context, the highest and lowest average Personal Context is in the Scientific Context and the maximum score achievement is obtained for Occupational and Scientific Contexts

Keywords: mathematical literacy, content, context, competence, problem solving

\section{INTRODUCTION}

Prospective elementary school teachers who are graduates of Elementary School Teachers Education (ESTE) Ganesha University of Education in general have high school and vocational school educational backgrounds. They are accepted as ESTE students through a selection that is conducted nationally and independently (locally). Participants of independent selection in general are participants who do not pass national selection. College students who pass through national selection come from high schools majoring in science, while those who pass independent (local) selection come from high schools majoring in science, social and from vocational schools. College

Citation: Suharta, I G. P., \& Suarjana I M. (2018). A Case Study on Mathematical Literacy of Prospective Elementary School Teachers. International Journal of Instruction, 11(2), 413-424. https://doi.org/10.12973/iji.2018.11228a 
students who pass national selection are placed in different classes with those who pass through independent or local selection. According to the secretary of the Department of ESTE who is also the lecturer of "Basic Mathematics and Mathematics Education Concepts" that the students' skill, interest, attitude, cooperation received through national selection is very good, while the class in which the students are accepted through independent selection is very weak. On the other hand, they will be dealt with similar situations and demands when becoming teachers, such as developing students' Mathematical Literacy (ML).

Wagner, DA (2011) says that literacy is the core of education for all. Similarly, in mathematics education, ML should be the core in mathematics learning. Wilkins (2000) who states that ML includes mathematical material knowledge, mathematical reasoning, understanding of social effects and the benefits of mathematics, understanding the nature and historical development of mathematics and mathematical dispositions. Venkat \& Graven (2008) defines ML as a concept related to mathematics but is different in its nature and purpose. Related to this, Organisation for Economic Co-Operation and Development (OECD) (2013) claims that ML is the ability of individuals to formulate, apply, and interpret mathematics in various contexts.

Results of research conducted by Program for International Student Assessment (PISA) on 15-year-old students shows that Indonesian students' ML is very low. This is reinforced by the results of research conducted by Mahdiansyah and Rahmawati (2014) that Indonesian High School (HS) students' ML is low. Results of research conducted by Andi Harpeni Dewantara, Zulkardi, \& Darmawijoyo. (2015) indicate that students' skills in solving ML problems is not maximum yet. Quantitatively, the result shows that the highest percentage of students' skills is $52.55 \%$, namely in interpretation tasks.

One of the factors that leads to low student ML skills is prior experiences. Development of students' skills in ML needs to be performed since elementary school because elementary school education will affect education at the next level. Because students' performance is highly dependent on teachers' performance, and elementary school teachers's skills are strongly influenced by their previous skills or experiences then describing Prospective Elementary School Teachers' ML is very important to provide input to revitalization of mathematics course curriculum at Department of ESTE as the effort of ML improvement. Based on this, the problem of this research is "how the Mathematical Literacy of Prospective Elementary School Teachers is".

\section{LITERATURE REVIEW}

Mathematical literacy involves more than a problem-solving procedure. This implies as a knowledge base, competence and confidence to apply this knowledge in the practical world. Mathematical literacy means being able to read, interpret data, solve daily problems, reason in numerical, graphic, and geometric situations, and communicate using mathematics (Bobby Ojase, 2011). According to OECD (2013) Mathematical literacy is an individual's capacity to formulate, employ, and interpret mathematics in a variety of contexts. It includes reasoning mathematically and using mathematical concepts, procedures, facts, and tools to describe, explain, and predict phenomena. It 
assists individuals to recognise the role that mathematics plays in the world and to make the well-founded judgments and decisions needed by constructive, engaged and reflective citizens. In accordance with this, then $\mathrm{ML}$ is related to : (1) a person's ability to formulate, use, and interpret mathematics in a variety of contexts, (2) using mathematical reasoning, concepts, procedures, facts, and tools to describe, explain, and predict phenomena, and (3) providing benefits about the role of mathematics in the real world. According to De Lange (2006) ML deals with real problems. It is intended that a problem is not purely mathematical but placed in certain situations. Students must solve real-world problems needing to use the skills and competence gained through school and life experiences. Therefore, ML is something strategic that must be developed. In other words, learning math at school should be oriented to improving ML.

Real-world problem solving essentially requires competence and is about content and context. This competence includes the ability to reason, make decisions, solve problems, interpret information, and communicate, as well as apply technology. Students should be provided with real-world content and context to develop the competence. When teachers implement ML learning and assessment, they should teach and assess mathematical content in a variety of contexts. This is in accordance with OECD (2010) which states that the ML construction developed by PISA consists of (3C), i.e. Content, Context, and Competence.

\section{a.Content}

On content, PISA divides it into 4 parts as following:

a.1 Quantity, is the most challenging and most essential aspect of mathematics in life. This category is related to the relationship of numbers and number patterns, including the ability to understand the size, the pattern of numbers, and everything related to the Numbers in daily life.

a.2 Space and Shape, includes phenomena related to the visual world that involves patterns, properties of objects, positions and orientations, representations of objects, encoding information visual, navigation, and dynamic interactions relating to the real form. This category is an aspect of Geometric Content in mathematics present in the curriculum.

a.3 Uncertainty and Data, includes the introduction of a place from a variation of a process, the meaning of quantification of the variation, knowledge of uncertainty and error in measurement, and knowledge of opportunity/chance. This content is related to the Probability and Statistics materials.

a.4 Change and relationship deal with aspects of algebraic contents and functions. Algebra, equations, inequalities, representations in the form of tables and graphs are central in describing, modeling, and interpreting changes in a phenomenon. Data interpretation is also an essential part of the problem in the Algebra and Functions category.

\section{b. Context}

Stacey $(2010 ; 2011)$ emphasizes the importance of context in learning, because students are prepared to welcome future challenges. The questions on PISA involve four Contexts, namely relating to Personal, Occupational, Societal, and Scientific Contexts.

b.1 A Personal Context that directly relates to the daily activities of the individual student. In living daily life, students definitely encounter various personal problems that require 
immediate solution. Mathematics is expected to play a role in interpreting the problem and then solving it.

b.2 Occupational Context relating to the life of students at school or in the workplace environment. Students' knowledge of mathematical concepts is expected to help to formulate, classify problems, and solve educational and occupational problems in general.

b.3 Societal Context relating to the use of mathematical knowledge in social life and the wider environment in daily life. Students can contribute their understanding of mathematical knowledge and concepts to evaluate various relevant circumstances in social life.

b.4 Scientific Context specifically relating to more abstract scientific activities and demanding the understanding and mastery of theory in solving mathematical problems.

c. Competence

Menurut OECD (2010), competence in PISA are called competency clusters, consisting of Knowledge Competencies, using Routine Procedures, using Multistep Procedures, and Reasoning.

Knowledge Competence is characterized by : (1) calculating using the sum total operation, subtraction, multiplication, and division; finding numbers; estimation; calculating percentage of given quantity, measurement, (2) knowing and using vocabulary in an equation, formula, bar graph, pie chart, cartesian field, table of values, mean, median and mode, (3) knowing and using formulas such as rectangular, triangle, circle areas; (4) reading the information in the table.

Competence using Routine Procedures is characterized by: (1) performing the procedure appropriately in a familiar context. Students know what procedure is required from the way the problem is presented. All information needed to solve the problem is immediately provided to students, (2) solving equations by means of trial and repair or algebraic processes, (3) drawing data graph for available data, (4) creating algebraic graph for given equations, (5) measuring dimensions such as length, weight and time using accurate measuring instruments that are sensitive to accuracy.

Competence using Multistep Procedures is characterized by: (1) solving problems using familiar procedures. However, the required procedures are not immediately visible from the presented problem. Students should decide on the most appropriate procedure to complete the solution and may have to perform one or more preliminary calculations before determining the solution; (2) selecting the most appropriate data from the options in the value table to solve the problem; (3) determining the best way to represent data to create a particular impression.

Reasoning Competence is characterized by: (1) asking and answering questions about what math they need to solve problems and then select and use the mathematical content; (2) interpreting the solution they specify for the problem in the context of the problem and if necessary to adjust the mathematical solution to make sense in its context; (3) criticizing for solving problems and statements about situations undertaken by others, (4) making generalizations of patterns observed in situations, making predictions based on patterns and / or other evidence and determining conditions that will produce the desired results. 


\section{METHOD}

\section{Research design}

This research essentially aims to give a detailed description of Prospective Elementary School Teachers' ML. Therefore, the research design used is qualitative with Case Study. Respondents of the research are assigned 12 Prospective Elementary School Teachers consisting of 6 men ( 3 men with strong mathematical skills and 3 men with weak mathematical skills) and 6 women ( 3 women with strong mathematical skills and 3 women with weak mathematical skills). Another characteristic is their age $21-23$ years, following the study in the Department of ESTE starting in the academic year 2013/2014, graduating in June-July 2017. The selection of respondents who have strong and weak mathematical skills is performed by the lecturers of Basic Mathematics Concepts course based on lecturers' observations and daily notes related to students' performance during lectures and in performing tasks.

\section{Instruments and Data Collection Techniques}

The instruments used to obtain research data are tests and interview guidelines. The test used has been declared valid and reliable with index 0.81 (Widya Suryaprani, 2017). This test is developed in reference to the 2006, 2009, 2012 PISA tests, consisting of 15 items each representing the following Content, Context, and Competence.

Table 1

Mathematical Literacy Test

\begin{tabular}{clll}
\hline Item number & Contents & Contexts & Competencies \\
\hline 1 & Number & Personal & Knowledge \\
\hline 2 & Number & Societal & Reasoning \\
\hline 3 & Number & Occupational & Using multistep procedure \\
\hline 4 & Number & Scientific & Using routine procedure \\
\hline 6 & Geometry & Occupational & Using routine procedure \\
\hline 7 & Geometry & Personal & Using multistep procedure \\
\hline 8 & Geometry & Scientific & Reasoning \\
\hline 9 & Geometry & Societal & Knowledge \\
\hline 10 & Probability and Statistics & Scientific & Using multistep procedure \\
\hline 11 & Probability and Statistics & Personal & Knowledge \\
\hline 12 & Probability and Statistics & Occupational & Using routine procedure \\
\hline 13 & Algebra and Functions & Occupational & Using multistep procedure \\
\hline 14 & Algebra and Functions & Scientific & Using routine procedure \\
\hline 15 & Algebra and Functions & Personal & Knowledge \\
\hline
\end{tabular}

Interviews are used to verify or complete the quantitative data.

The procedure for conducting the research can be described below.

a. The research was conducted on June 22, 2017, beginning with an explanation of the purpose of test execution as well as brief information about the importance of ML. Emphasized once to work independently.

b. Respondents were given the test along with the necessary equipment with working time within 120 minutes. 
c. After a 30-minute break, proceeded with a structured interview to all respondents to verify students' answers.

d. On July 5, 2017 tests and interviews were conducted again to 3 (three) respondents each of whom got high, moderate, and low ML scores. The focus of the test was to rework the questions that could not be answered during the first test, while the interview was conducted for verification, deepening, or completing data related to ML.

\section{Data analysis technique}

Data on Prospective Elementary School Teachers' ML are analyzed descriptively. Mathematical literacy is classified into high, medium, and low with the ML classification conversion guidelines established using modified benchmark norms from the Ganesha University of Education Handbook as follows.

If the average score $>80 \%$ then it is classified high

If $65 \%<$ the average score $\leq 80 \%$ then it is classified medium

If the average score $\leq 65 \%$ then it is classified low.

(UNDIKSHA, 2016)

\section{FINDINGS}

The number of ML test items is 15 .. The scoring rubric using the holistic type with a score of each item is 10 , so the maximum score is 150 . All test result scores are converted to a scale of 100 . Based on the first and second test results, ML in detail is as follows.

Table 2

Mathematical Literacy

\begin{tabular}{lllll}
\hline \multirow{2}{*}{ Descriptive Statistics } & \multicolumn{2}{c}{ Mathematical Skill } & \multicolumn{2}{c}{ Gender } \\
\cline { 2 - 5 } & Strong & Weak & Male & Female \\
\hline Maximum Score & 77.33 & 66.67 & 76.00 & 77.33 \\
\hline Minimum Score & 33.33 & 14.67 & 14.67 & 44.00 \\
\hline Average & 57.33 & 43.78 & 42.89 & 58.22 \\
\hline Deviation Standard & 20.47 & 19.03 & 23.51 & 14.05 \\
\hline Classification & Low & Low & Low & Low \\
\hline
\end{tabular}

In accordance with Table 2 above, ML respondents who have strong or weak mathematical skills are in a low classification. However, from the average, the maximum score, and the minimum score, then the ML respondents who have strong skills higher than those who have weak ability. Similarly, male and female ML respondents are in low classification. However, from the average, maximum score, and minimum score, then the female ML respondents are better than male respondents.

From the Content, Contexts, dan Competence, Prospective Elementary School Teachers' ML can be presented as the following table. 
Table 3

$\underline{\text { Results of statistical analysis when viewed from Content, Context, and Competency }}$

\begin{tabular}{llllll}
\hline $\begin{array}{l}\text { Literacy } \\
\text { Components }\end{array}$ & Literacy Descriptor & $\begin{array}{l}\text { Maximum } \\
\text { Score }\end{array}$ & $\begin{array}{l}\text { Minimum } \\
\text { Score }\end{array}$ & Average & $\begin{array}{l}\text { Deviation } \\
\text { Standard }\end{array}$ \\
\hline \multirow{4}{*}{ Contents } & Number & 95.00 & 0.00 & 49.58 & 38.82 \\
\cline { 2 - 6 } & Geometry & 75.00 & 25.00 & 50.00 & 14.77 \\
\cline { 2 - 6 } & Probability and Statistics & 80.00 & 0.00 & 55.00 & 22.59 \\
\cline { 2 - 6 } & Algebra and Functions & 85.00 & 20.00 & 48.75 & 22.58 \\
\hline Contexts & Occupational & 100.00 & 10.00 & 62.08 & 28.00 \\
\cline { 2 - 6 } & Personal & 66.67 & 0.00 & 74.44 & 41.18 \\
\cline { 2 - 6 } & Societal & 80.00 & 10.00 & 35.83 & 7.33 \\
\cline { 2 - 6 } & Scientific & 100.00 & 25.00 & 33.75 & 19.20 \\
\hline \multirow{3}{*}{ Competencice } & Knowledge & 100.00 & 25.00 & 71.67 & 22.39 \\
\cline { 2 - 6 } & Using routine procedure & 100.00 & 10.00 & 70.00 & 29.15 \\
\cline { 2 - 6 } & Using multistep procedure & 75.00 & 10.00 & 29.58 & 25.00 \\
\cline { 2 - 6 } & Reasoning & 60.00 & 0.00 & 24.44 & 19.56 \\
\hline
\end{tabular}

In accordance with Table 3 above, in terms of content, the highest score is achieved on the number content, which is 95 and the lowest on the geometry content of 75 . Based on the average score, the weakest content is in terms of Algebra and Function, with an average of 48.75, while the strongest in the Chance and Statistics field with an average of 55.00. The deviation standard is relatively the same, i.e. 22.59 and 22.58, and the maximum score in Algebra and Function content is better than the Probability and Statistics Content.

In terms of Context, the average personal context has the greatest average of 74.44 and the lowest is in the Scientific Context. From the aspect of maximal score achievement, the score obtained for Occupational and Scientific Context is 100. However, the deviation standard of the Personal Context is the largest so that the variation of the score is quite high. In terms of competence, the highest average is for Knowledge Competence that is equal to 71.67 whereas the lowest in Reasoning Competence with an average of 24.44. For questions of Reasoning Competence, the maximum score is 60 , the minimum is 0 and the deviation standard is 19.56. These results indicate that none of the respondents can solve the problem of ML Reasoning Competence, and the score variation is relatively high. Some questions can be understood well, but because the respondents forget the concept then the questions cannot be answered well. As indicated by female respondents who have strong math with code B1, as follows.

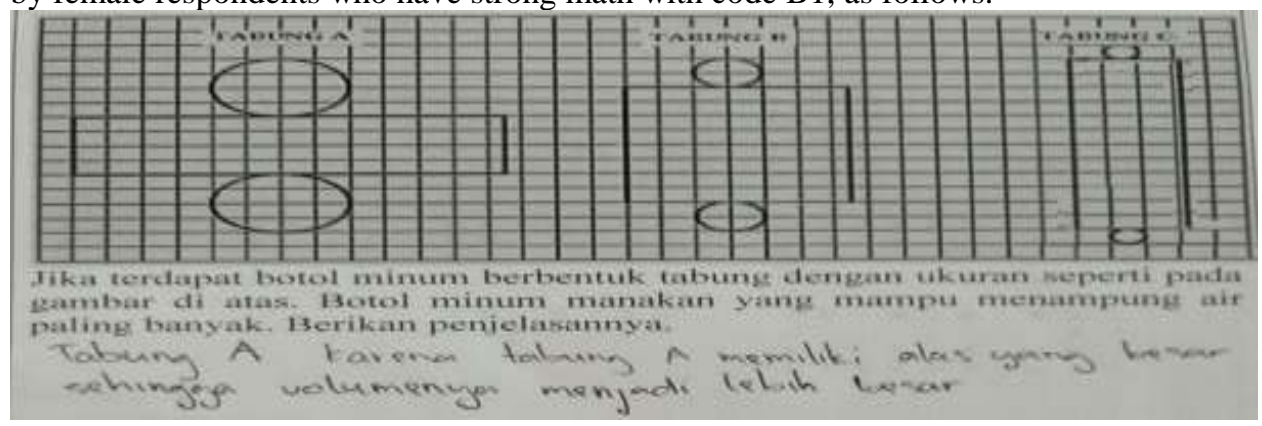


If there is a tube drinking bottle with the size as in the picture above, which drinking bottle can hold the most water? Give an explanation!

Tube A because tube A has a large base so that the volume becomes larger as well.

Fragment 1

Interview with B1

Researcher: try to see the answer key for this problem ....(the researcher's finger pointing to the question and answer key)

B1 : my answer is correct.tube A

Researcher: good.... what is known and asked by this question?

B1 : the diameter of the base and the height of the tube and what is asked is the most tube volume ...

Researcher: where do you know the diameter of the base and the height of the tube from?

B1 : from counting the boxes on the image..

Researcher: what is the formula of tube volume? ...

B1 : ee....(trying to think).. I don't remember, Sir.

It seems that in the 5th row the respondent understands the problem well, but in the last line it shows that he/she forgets the concept so that he/she cannot perform the solving procedure well.

\section{DISCUSSION}

Mathematical Literacy contains elements of Content, Context, and Competence. The content element consists of Numbers, Geometry, Probability and Statistics, as well as Algebra and Functions. The context elements are Personal, Occupational, Societal, and Scientific. Meanwhile, competence consists of Knowledge, using Routine Procedures, using Multistep Procedures, as well as Reasoning. This test is used for children aged \pm 15 years. In general, the substance of the tested material has been studied by the students at the junior high school level and strengthened in the next level of educational unit.

The low skills of Prospective Elementary School Teachers' ML in Ganesha University of Education based on differences in mathematical skills and gender can be understood because they are designed as non-routine mathematical problems, associated with context, and require high-level thinking. Understanding the problem is not enough but the problem solver should be able to see the concepts, the relevant procedures and apply them. In addition, the low skills in ML can be caused by not knowing or forgetting the concept that must be used. As revealed in the "that they forget the concept" interview. The interview quote to one of the respondents is male and his mathematical skill is weak, with code A4 is as follows.

Fragment 2

Interview with A4

Researcher : how ... Can you do it all? 


$$
\begin{array}{ll}
\text { A4 } & : \text { no..I forget much } \\
\text { Researcher } & : \text { is it relevant to the given mathematics course? } \\
\text { A4 } & : \text { a little...it is only the cubes. }
\end{array}
$$

This is supported by another respondent who also said that because the question is difficult, he/she has forgotten. This statement is also supported by a description of the mathematics course for the Prospective Elementary School Teachers of Ganesha University of Education and the opinion of mathematics lecturers who stated that in general the focus of the mathematics course for ESTE Students in Ganesha University of Education is mathematics in elementary school. Some relevant concepts such as probability theory and geometry are given, but not in depth. There seems no material review yet that improves mathematical thinking skills, so students with strong mathematical skills are particularly strong in mathematics and elementary school mathematics learning but are not followed by reasoning, problem solving, or reflection skills.

From the development of science and technology and parenting patterns, there tends to be no difference in parenting patterns towards boys and girls. Parents tend to provide the same facilities, support, or opportunities to both boys and girls. This parenting pattern will give them the color of how they think and equal development between two hemispheres (right or left). In accordance with this, the female ML respondents should be relatively the same as the male respondents. However, the finding of this research is that the ML average of the female respondents is better than the ML average of the male ones.

Respondents can solve problems of knowledge competence. Problems classified as knowledge competence are characterized by: (1) calculating using the sum total operation, subtraction, multiplication, and division; finding numbers; estimation; calculating percentage of given quantity, measurement, (2) knowing and using vocabulary in an equation, formula, bar graph, pie chart, cartesian field, table of values, mean, median and mode, (3) knowing and using formulas such as rectangular, triangle, circle areas; (4) reading the information in the table. Here is an example of an answer:

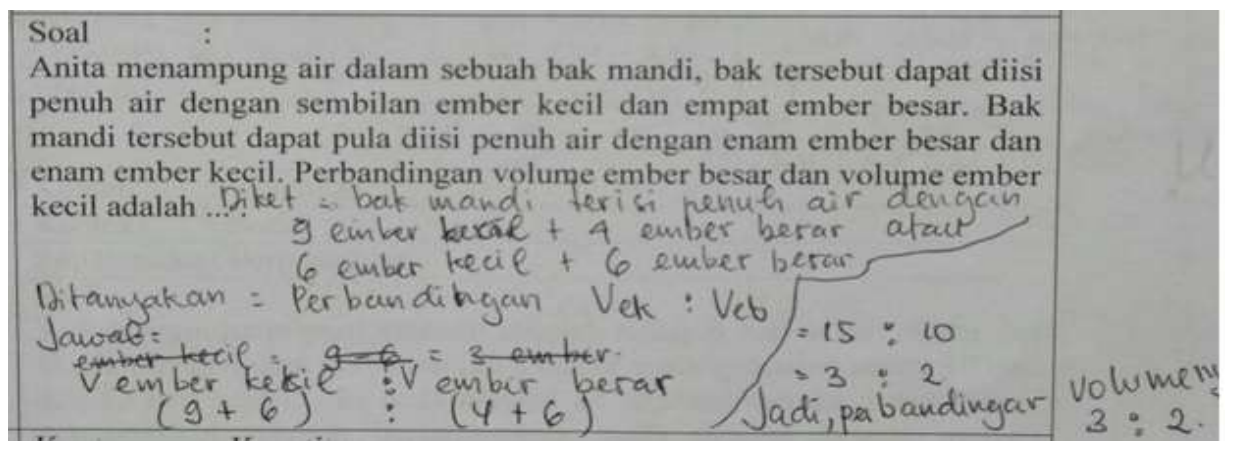


Question :

Anita holds water in a bathtub. The tub can be filled with nine small buckets and four large buckets. It can also be filled with water with six large buckets and six small buckets. Comparison of large bucket volume and small bucket volume is ...

Known : The tub is filled with 9 small buckets +4 large buckets or 6 small buckets +6 large buckets

Asked : Vsb : Vlb ?

Answer: $\quad$ Small bucket volume : $\quad$ Large bucket volume

$$
\begin{array}{lll}
(9+6) & : & (4+6) \\
15 & : & 10 \\
3 & : & 2
\end{array}
$$

So. the volume comparison is $3: 2$.

Knowledge competence problem is answered very well, ranging from understanding the problem, using counting operations, and being able to use the concept of comparison. On the other hand, the question of reasoning competence cannot be answered yet by all students. In example of the reasoning competence problem is as follows.

The taxi fare for the first kilometer is Rp8.000,00 and for the next kilometer is Rp $4.000,00$. The fee for the waiting time is $\mathrm{Rp} 30.000,00$ / hour. If the distance is less than $2 \mathrm{~km}$, then the passenger must pay Rp 20.000,00. Make a mathematical model for the cost required by a passenger, if he or she takes the taxi and asks the driver to wait.

Some students can understand the meaning of the problem, but do not know the concept that must be used, and how to calculate it. It requires reasoning and the ability to connect phenomena from the second time onwards with the costs to be incurred before the second time and interpret the results to fit the context.

Similarly, in the following reasoning competence problem, Respondent's answer with strong mathematics and female respondent is shown as follows.

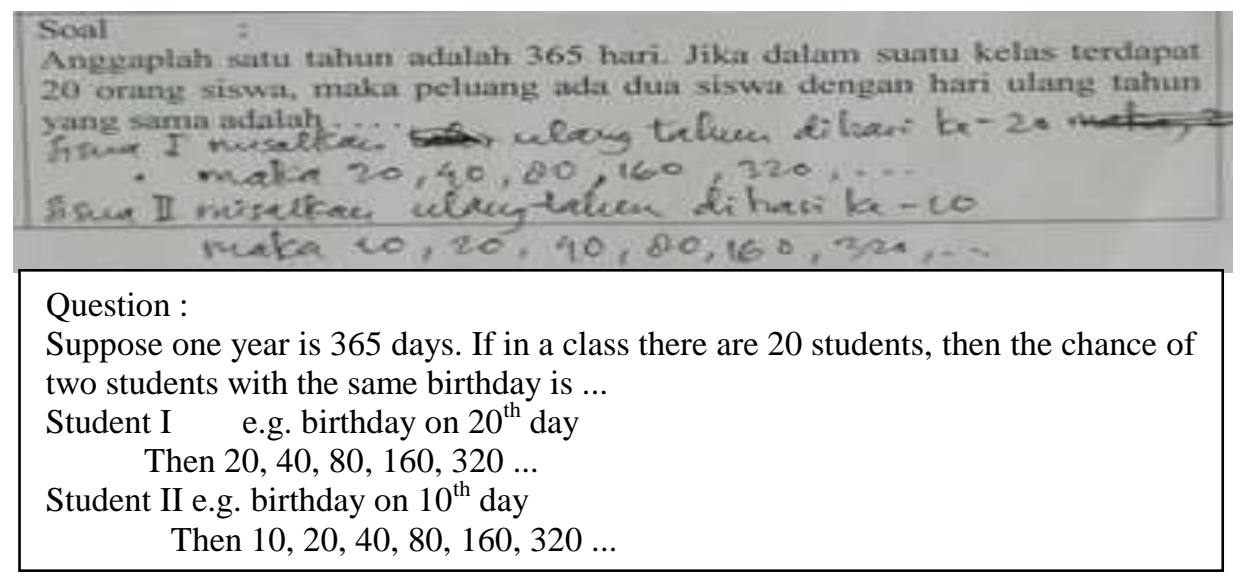


The student's answer indicates that the student does not know the relevant concept that should be used. These results are reinforced by interviews to female respondents whose mathematical skills are weak, with the code B6 as follows.

Fragment 3

Interview with B6

Research: what does this question mean? (pointing to the question)

B6 : there are 20 children dan what is asked is the chance of two children with the same birthday

Research: do you remember the concept of chance of an event?..

B6 : I forgot...ee.. I don't like chance

In the last line of the interview result, it is clearly shown that she forgot and disliked the chance material. This is a strong factor that allegedly leads to low ML of Prospective Elementary School Teachers in Ganesha University of Education.

\section{CONCLUSION}

Based on the previous description, some things can be concluded as follows.

a. Mathematical Literacy is the individual's skill to formulate, apply, and interpret mathematics in various contexts. This skill includes mathematical reasoning and the ability to use facts, concepts, and mathematical procedures to describe, explain and predict a phenomenon. Mathematical Literacy is an important aspect and is the core of mathematics learning since elementary school, including for ESTE Students..

b. Mathematical Literacy of Prospective Elementary School Teachers from the aspect of mathematical skills and gender is low. However, respondents who have strong mathematical skills show better ML than respondents who have weak mathematical skills. Similarly, female respondents show better ML than male respondents.

c. In terms of content, the highest score is achieved on the Numbers content, which is 95. Based on the average score, the weakest content is in terms of Algebra and Function, while the strongest is in the Probability and Statistics field. However, the maximum score in Algebra and Function Content is better than the Probability and Statistics Content. In terms of Context, the average of the highest and lowest Personal Contexts is in the Scientific Context. From the aspect of maximum score achievement, the score obtained for Occupational and Scientific Context is 100. In terms of Competence, the highest average is for Knowledge Competence and the lowest is in Reasoning Competence. Some respondents can solve all the problems on the Knowledge Competence, while the problem on the Reasoning Competence none of the respondents are able to solve all the problems and even there are respondents who cannot solve all the problems.

In accordance with the above conclusion, it is suggested to: (1) other researchers to conduct more extensive and in-depth research related to ML in terms of different gender, and (2) manager of Department ESTE in Ganesha University of Education to revitalize the curriculum of mathematics courses that extend or deepen the mathematics material and integrate the corresponding competencies to teach and improve the ML. 


\section{REFERENCES}

Andi Harpeni Dewantara, Zulkardi, \& Darmawijoyo. (2015). Assessing Seventh Graders' Mathematical Literacy In Solving Pisa-Like Tasks. IndoMS-JME, 6(2).39-49

Bobby, O. (2011). Mathematics Literacy: Are We Able To Put The Mathematics We Learn Into Everyday Use?. Journal of Mathematics Education, 4(1), 88-100

De Lange, J.(2006). Mathematical Literacy For Living From OECD-PISA Perspective. Tsukuba Journal of Educational Study in Mathematics. 25(-),13 - 35

Mahdiansyah dan Rahmawati (2014). Literasi Matematika Siswa Pendidikan Menengah: Analisis Menggunakan Desain Tes Internasional dengan Konteks Indonesia. Badan Penelitian dan Pengembangan, Kemdikbud

OECD [Organisation for Economic Co-Operation and Development] (2010). PISA 2012 Mathematics Framework. Paris: OECD Publishing

OECD [Organisation for Economic Co-Operation and Development] (2013). PISA 2012 Assessment and Analytical Framework: Mathematics, Reading, Science, Problem Solving and Financial Literacy. Paris: OECD Publishing.

Parakitipong, N., \& Satoshi, N. (2006). Analysis of Mathematics Performance of Grade Five Students in Thailand Using Newman Procedure. Journal of International Cooperation in Educatio, 9(1), 111-122

Stacey, K. (2010). Mathematical and Scientific Literacy Around The World. Journal of Science and Mathematics Education in Southeast Asia, 33(1), 1-16.

Stacey K. (2011). The PISA View of Mathematical Literacy in Indonesia. IndoMS.JME, (2), 95-126

UNDIKSHA. (2016). Pedoman Studi Program Sarjana dan Diploma. Singaraja: Undiksha.

Venkat, H., \& Graven, M. (2008). Opening up spaces for learning: Learners' perceptions of mathematical literacy in grade 10. Education As Change, 12(1), 29-44.

Wagner. D. A. (2011). What happened to literacy? Historical and conceptual perspectives on literacy in UNESCO§ International Journal of Educational Development, 319-323

Widya, Suryaprani (2017). Hubungan Jenis Kelamin, Literasi Matematika, dan Disposisi Matematika Terhadap Prestasi Belajar Matematika Peserta didik SMA Negeri Di Denpasar. Thesis (unpublished). Singaraja: Undiksha

Wilkins, J. L. M. (2000). Preparing for the 21st century: The status of quantitative literacy in the United States. School Science and Mathematics, 100(8), 405-418. 